\section{Subject-determined postfeedback interval in auditory concept identification}

\author{
LEROY MATTHEWS \\ Idaho State University, Pocatello, Idaho 83201
}

In a two-category three-dimensional concept learning task, a free-choice postfeedback interval (PFI) was allowed in one group, while another group received a mandatory 2-sec PFI. No differences in-performance were observed. When PFI latencies were analyzed, all latencies decreased on successive trials, were longer following errors than following correct classifications, and were longer for the more difficult-to-learn dimension. These data were interpreted as supporting the hypothesis that information processing follows both correct and incorrect classifications.

There is substantial support for the hypothesis that Ss who are allowed a longer intertrial interval (postfeedback interval, PFI) learn the relevant dimension in a concept identification task faster than Ss who are not allowed the additional length of time (Bourne \& Bunderson, 1963; Bourne, Guy, Dodd, \& Justesen, 1965). It is presumed that the longer PFI allows the $S$ a greater opportunity in which to use memory or to engage in other problem-solving activity.

An implication of the all-or-none learning models of Trabasso \& Bower (1966) and Restle (1962) is that the PFI should have facilitative value to the $S$ only after an error, since it is assumed that after a correct classification the $S$ simply maintains his current strategy. Bourne, Dodd, Guy, \& Justesen (1968) found that while a longer PFI facilitated performance, it was not limited to groups allowed a longer PFI only after an error, but to groups who were allowed a longer PFI only after a correct classification as well. The results of their study provided support for an alternative theory, such as Levine's (1966), which does not imply that learning occurs after error trials only.

In the present study, it was reasoned that if Ss were allowed to determine their own PFI following each trial (rather than a fixed interval) results similar to those found by Bourne et al (1963, 1965, 1968) should occur. That is, groups allowed to determine their own PFI should have longer PFI durations than a 2 -sec control group and consequently learn the relevant concept faster. Furthermore, allowing free-choice PFIs provides a basis for determining the relative extent to which Ss engage in information processing during

*The author would like to express his appreciation to Frank Pelfrey for his assistance in collecting the data. acquisition. Consequently, free-choice PFI latencies were examined as a function of the correctness of the previous response and task difficulty. SUBJECTS

A total of 44 students enrolled in an introductory psychology course at Idaho State University served as Ss. Participation in the study was a part of their course requirement. The experimental conditions were arranged in random order, and each $S$ was assigned to each successive condition upon arrival for testing. APPARATUS AND

STIMULUS MATERIALS

The auditory stimuli consisted of three defined dimensions with two values on each. Each tone was either 5 or $2 \mathrm{sec}$ in duration, 1,000 or $500 \mathrm{~Hz}$ in frequency, and continuous or with a break of $.5 \mathrm{sec}$ duration occurring midway through the tone. Tones were generated with a Heathkit audio generator. Each of the eight different combinations of tones possible from these dimensions was placed in 10 different random orders and put on tape. The tone was presented to the $S$ with a Roberts 720 tape recorder and timing of the intervals was made possible with a stopwatch. The continuous-break dimension was never used as the relevant dimension.

$$
\text { DESIGN }
$$

The design was a 2 by 2 factorial with independent observations. The difficulty variable was the relevant dimension during training, either duration (D) or frequency (F). The other variable was whether or not the $S$ was allowed to determine his own PFI (PFI) or allowed a fixed 2-sec PFI (C).

\section{PROCEDURE}

Each $S$ was seated and read instructions to the effect that the task would entail classifying different sounds. Each of the eight different tone combinations was presented and identified for the $S$. Each $S$ was then asked to identify each of the dimensions and the respective values of each. Following this procedure, the $\mathrm{E}$ told the $\mathrm{S}$ to classify each of the tones as belonging to either an " $A$ " or " $B$ " category. The $S$ was told that he could have as long as he wanted in which to classify each sound; however, if more than $1 \mathrm{~min}$ elapsed, the $\mathrm{E}$ encouraged a response. Immediately after the $S$ responded, the $S$ was informed of the appropriate classification. The task continued until $S$ correctly classified eight consecutive sounds. The Ss in the PFI groups were given the additional instruction that following the informative feedback after each classification, they could regulate the time interval before proceeding to the next sound. Each $\mathbf{S}$ was instructed to indicate to the E when he wanted to hear the next sound. This interval was recorded by $\mathrm{E}$ and is designated as PFI latency. The C group Ss were allowed a 2-sec PFI only.

The initial analysis consisted of comparing the various groups on total instances prior to criterion. The means and standard deviations were: Group $\mathrm{F}, \overline{\mathrm{X}}=6.50, \quad \mathrm{SD}=8.27$; Group $D, \quad \bar{X}=14.44, \quad S D=9.76$ Group C, $\bar{X}=9.76, \quad S D=12.21$; Group PFI, $\bar{X}=9.33, \mathrm{SD}=7.90$. Using a 2 by 2 factorial design, the only significant difference found was between Group $F$ Ss who required fewer trials to reach criterion than Group D Ss $(F=8.43, d f=1,40$, $\mathrm{p}<.01$ ).

An analysis of the PFI latencies was made using a 2 by 2 repeated measures design in which task difficulty was one variable and latency following an error or a correct response was the other variable. An average latency for each $S$ was determined by summing all error or correct latencies prior to criterion and dividing by the number of error or correct responses committed. A reciprocal transformation was performed on all average latencies for this analysis and all other subsequent latencies. It was found that Group D Ss had significantly longer average latencies than Group F Ss $(F=\mathbf{5 . 9 0}$, $\mathrm{d} f=1,20, \quad \mathrm{p}<.05), \quad$ and average latencies following an error were significantly longer than following a correct classification $(F=47.37$, $\mathrm{df}=1,20, \quad \mathrm{p}<.001$ ), with no significant interaction.

It was observed that average latencies during the initial phases of the task were longer than those during the later phases. Consequently, this variable was introduced for analysis. The total number of each Ss' error and correct responses prior to criterion were divided into those occurring during the first half of the task and those occurring during the second half. 
Table 1

Means and SDs of PFI Latencies Following Error and Correct Responses for First Half, Second Half, and Combined Trials as a Funetion of Easy and Difficult Relevant Dimensions

\begin{tabular}{|c|c|c|c|c|c|c|}
\hline & & & First & Second & Combined & Critarion \\
\hline \multirow{2}{*}{ Easy } & Error & $\begin{array}{l}\bar{X} \\
\text { SD }\end{array}$ & $\begin{array}{r}11.59 \\
5.50\end{array}$ & $\begin{array}{r}10.48 \\
6.50\end{array}$ & $\begin{array}{r}11.15 \\
5.74\end{array}$ & \\
\hline & Correct & $\begin{array}{l}\bar{X} \\
S D\end{array}$ & $\begin{array}{l}5.00 \\
2.10\end{array}$ & $\begin{array}{l}4.60 \\
2.50\end{array}$ & $\begin{array}{l}4.70 \\
1.30\end{array}$ & $\begin{array}{l}3.32 \\
1.15\end{array}$ \\
\hline \multirow{2}{*}{ Difficult } & Error & $\begin{array}{l}\bar{X} \\
\text { SD }\end{array}$ & $\begin{array}{r}19.24 \\
6.50\end{array}$ & $\begin{array}{r}11.15 \\
5.35\end{array}$ & $\begin{array}{r}15.48 \\
7.28\end{array}$ & \\
\hline & Correct & $\begin{array}{l}\overline{\mathbf{X}} \\
\mathbf{S D}\end{array}$ & $\begin{array}{l}8.06 \\
2.50\end{array}$ & $\begin{array}{l}6.10 \\
3.21\end{array}$ & $\begin{array}{l}6.40 \\
1.62\end{array}$ & $\begin{array}{l}4.25 \\
1.52\end{array}$ \\
\hline
\end{tabular}

Each average latency was computed separately for each half of the task. Scores of one $S$ from Group $D$ and three from Group $\mathrm{F}$ had to be dropped from the analysis because they did not have at least two error and two correct classifications prior to criterion. With the addition of this variable, the resulting 2 by 2 by 2 repeated measures analysis provided the same findings as those with the previous analysis, with the additional finding that average latencies during the first half of the task were longer than those during the second half (F=7.55, df $=1,48, p<.01$ ). There were no significant interactions. The means of the average latencies of these groups are presented in Table 1.

A final analysis was performed between average latencies during the first and second half and during criterion following correct responses only. A significant difference in average latencies was found $(F=11.15, \mathrm{df}=2,34, \mathrm{p}<.01)$. The means of the average latencies of these groups are presented in Table 1.

\section{DISCUSSION}

The hypothesis tha Ss who are allowed a free-choice PFI should learn the task faster than fixed 2-sec control So was not supported. While the PFI may have been optimal for Ss in the PFI groups, the additional time did not facilitate performance. These results are not consistent with those of Bourne et al $(1963,1965,1968)$, who found facilitation with an extended PFI. There is the possibility that allowing a free-choice PFI alters the strategy the $\mathbf{S}$ would normally use. For some Ss, the free-choice may encourage additional use of memory which they may not normally use, while for others it may encourage a strategy which demands little use of memory. The result would be more variability in solution attainment which could account for a failure to find facilitation. However, since the task was relatively easy for most Ss, regardless of their respective condition, the 2-sec PFI allowed the $C$ groups may have been sufficient to maintain adequate memory.

When the PFI latencies were anlyzed, three significant findings were observed. Free-choice PFI latencies decreased on successive trials, were longer following errors than following correct classifications, and were longer when the relevant dimension was more difficult to learn.

There are at least two possibilities which may have accounted for the decrease in latencies on successive trials. First, there is the possibility that Ss may not have remembered to inform the $E$ when they wanted the next stimulus to appear during the initial trials. This variable could be controlled by requiring extensive pretraining trials. If latencies following correct trials decreased or were relatively short following pretraining, support would be given to an assumption that little or no information processing occurs after a correct response. Second, assuming the decrease was related to information processing, there is the implication that information processing followed both types of responses. This interpretation is not consistent wiht the after-error-only assumption of Restle (1962) or Trabasso \& Bower (1966). However, it is consistent with Levine's (1966) assumption that information processing occurs following correct as well as following incorrect classifications.

According to Levine (1966), following a correct classification, the $\mathbf{S}$ selects a hypothesis consistent with the stimulus attributes he had selected on the previous trial. However, following an error, the $S$ is confronted with selecting a hypothesis consistent with the attributes he did not select on the previous trial. This is a more difficult requirement for the $S$ which would be consistent with the finding that PFI latencies were longer following errors. These assumptions would also account for the finding that all PFI latencies decreased on successive trials, since $S$ was presumably eliminating information on successive trials.

All Ss received identical stimuli, but those who were required to learn the duration dimension required a greater number of trials to reach criterion and chose longer PFI durations. These data suggest that $S$ s did not consider all stimulus attributes at once during the initial trials. The Ss may have chosen one or the other of the two other dimensions initially, but if one of these did not lead to solution, the attributes of the duration dimension were included. This interpretation would account for the greater number of trials to solution as well as the longer PFI durations, since additional information had to be processed when the duration dimension was included.

The results of this study appear to be in general agreement with the assumptions of Levine's (1966) theory. However, there remains the possibility that allowing an opportunity for free-choice PFI durations alters the strategy Ss would otherwise use with a short, fixed PFI. This question should be investigated in future research.

BOURNE, L. E.. \& BUNDERSON, C Effects of delay of informative feedback and length of post-feedback interval on concept identification. Journal of Experimental Psychology, 1963, 65, 1-5. BOURNE, L. E., JR., DODD, D., GUY, D. E. \& J U S T E S N D. R . Response-contingent intertrial intervals in concept identification. Journal of Experimental Psychology, 1968, 76, 601-608.

BOURNE, L. E., JR., GUY, D. E., DODD, D. \&USTESEN, D. R. Concept identification: The effects of varying length and informational components of the intertrial interval. Journal of Experimental Psychology, 1965, 69, 624-629.

LEVINE, M. Hypothesis behavior by humans during discrimination learning. Journal of Experimental Psychology, $1966,71,331-336$.

RESTLE, F. The selection of strategies in cue learning. Psychological Review, 1962 , $69,320-343$.

TRABASSO, T., \& BOWER, G. Presolution dimensional shifts in concept identification: $A$ test of the sampling with replacement axiom in all-or-none models. Journal of Mathematical Psy chology, 1966, 3, 163-173. 